\title{
Design of an Automatic Machine for Sensor Manufacturing by the GoP Technique
}

\author{
Luiz Antonio Rasia, $\mathrm{PhD}^{1}$, Antonio Carlos Valdiero, $\mathrm{PhD}^{2}$, Edmilton Stein, Mechanical Engineer ${ }^{3}$ and Carlos \\ Augusto Valdiero, Computer science ${ }^{4}$ \\ 1,3UNIJUI/DCEEng, Brazil, rasia@unijui.edu.br,e_stein@outlook.com \\ ${ }^{2}$ UFSC, Brazil, antoniocvaldiero@gmail.com \\ ${ }^{4}$ IFRS, Brazil, carlos_valdiero@hotmail.com
}

\begin{abstract}
As the industry advances toward the Advanced Manufacturing process emerges the need for more autonomous machines in order to get more agile and efficient production. Consequently, it creates the need for the design of cheap, easily manufactured and environmentally friendly sensors. Graphite on Paper (GoP) method for producing sensors is a strong candidate as an alternative to the currently available sensors since they meet all the requirements mentioned above. This technique consists of creating graphite layers onto a paper substrate in order to develop a piezoresistive sensor which shows to be suitable as temperature sensors as well as strain gauges with a wide application range, such as in force and temperature control, robotics, agricultural, biomedical engineering, automation, and control systems. Manual pencildrawing is the simplest way to exfoliate the carbon on the paper; however, this method generates uneven graphite layers on the substrate leading to unexpected results caused mainly by the high variation of the applied force during the manual exfoliation of the carbon films. Aiming to obtain more uniform graphite layers, a machine was developed to fabricate the sensors using a commercial mechanical pencil to apply the graphite on the substrate. The machine mainframe is built in steel in order to achieve robustness. It has three axes moved by two stepper motors and one direct current motor, the latter used together with a load cell and a microcontroller to control the applied force during the material exfoliation.
\end{abstract}

Keywords-GoP, Piezoresistive effect, Automatic machine, Graphite sensor.

\section{INTRODUCTION}

The "Industry 4.0" concept, first conceived in Germany now spreads throughout the world. According to [1], aiming to supply the need for more individualized products as a consequence of the modern market emerges a new industrial revolution known as the "4th Industrial Revolution", thus changing the industrial model from the large-scale production to the "batch size one" model. For this, it is necessary to introduce a set of concepts in the manufacturing system, where "Smart Factory" plays an essential role in this new industrial era, this term represents an increase on the level of automation, thus creating a need for more affordable and ecologically friendly sensors and actuators. Intending to supply this need arises the proposal of a piezoresistive sensor, made mainly of paper and graphite.

The sensor concerned in this paper is the strain gauge type piezoresistive sensor, obtained by the GOP - Graphite on Paper technique. Strain Gauges are sensors typically used to

Digital Object Identifier (DOI):

http://dx.doi.org/10.18687/LACCEI2020.1.1.250

ISBN: 978-958-52071-4-1 ISSN: 2414-6390 measure the strain of a component or structure under a load. The working principle of these sensors lies on the assumption that the sensor experiences all the strain caused by a load in a structure, so that resulting in a proportional change in its electrical resistance which can be easily measured. To know how much strain a body is experiencing during its use is of great importance since through it one can evaluate new or modified designs of a machine component or structure to ensure the most reliable and efficient product as possible. Furthermore, the use of strain gauges contributes to the enhancement and evaluation of the mathematical model used [2].

However the piezoresistive sensor obtained from the GoP technique itself has been proved to be flexible, low cost, lightweight, biocompatible and recyclable [3]. The reference [4] shows that the sensors some deviations that are believed to be related to the deposition method due to the manual deposition of the graphite on the substrate and / or in the nature of the materials. Conventional CMOS technology uses silicon as a substrate and cannot be flexible like the polymer proposed in this work. Silicon requires complex and expensive processes when compared to the GoP technique. This technique is laborious to produce sensors manually, showing non-uniformities during the processing steps.

The use of an automated machine with force and speed control allows producing fine traces of graphite on paper in a more uniform. This procedure is important for the manufacture of piezoresistors. Therefore, aiming to minimize these deviations in the results and to help to investigate the real cause of them as well as to attempt to make a serial production possible a machine was developed to deposit the graphite in more uniform and controlled layers.

The cost of the sensors cannot be directly assessed, taking into consideration that this manufacturing technique is relatively recent or even little exploited so far. I addition, there is no other machine in the market for cost comparison due to the control system used to control the graphite deposition by mechanical exfoliation on polymeric substrates. However, as the sensors do not contain any conventional material, such as Silicon, but only organic everyday materials such as commercial A4 paper and graphite cylinder, its cost can be considered lower than the traditional sensors.

As for the methodology an analysis was carried out to identify the project needs, which are to be able to obtain a uniform deposition of graphite on the substrate through a small variation on the pressure applied as well as being able to 
control the position of the graphite deposition. To meet this needs the machine model developed is similar to a traditional milling machine where a tool for graphite deposition is used instead of the milling cutter, it has three axes whose control occurs by a Computer Numerical Control (CNC). Aiming to control the pressure applied during the deposition of graphite a load cell was used together with a microcontroller board Arduino Uno, which utilizes the microcontroller ATmega328P, the human-machine interface was developed using the software Java to provide a consumer-friendly interface. The machine was designed using the Software Dassault Solid Works and its prototype developed at the University research group called GPMaD (Research Group on Materials and Devices).

Aiming to verify the machine repeatability, a set of fifty sensing elements was manufactured and, their electrical resistance was measured.

TABLE I

GRAPHITE CYLINDER PROPERTIES

\begin{tabular}{|l|c|c|c|}
\hline \multicolumn{4}{|c|}{ Commercial graphite type HB } \\
\hline Property & Value & $\begin{array}{c}\text { Unit of } \\
\text { Measurement }\end{array}$ & Source \\
\hline Electrical Resistance & 2.24 & $\Omega$ & $\begin{array}{c}\text { Multimeter } \\
{[9]}\end{array}$ \\
\hline Electrical Resistivity & $9.119 \times 10^{-5}$ & $\Omega \times \mathrm{m}$ & $=\frac{R A}{L}$ \\
\hline Length & $6.050 \times 10^{-3}$ & $\mathrm{~m}$ & Caliper \\
\hline Diameter & $5.600 \times 10^{-4}$ & $\mathrm{~m}$ & Micrometer \\
\hline Cross-sectional area & $2.463 \times 10^{-7}$ & $\mathrm{~m}^{2}$ & $A=\pi r^{2}$ \\
\hline Carbon & 68 & $\%$ & $\begin{array}{c}\text { Kaneko } \\
(2015)\end{array}$ \\
\hline Clay & 26 & $\%$ & $\begin{array}{c}\text { Kaneko } \\
(2015)\end{array}$ \\
\hline Wax & 5 & $\%$ & $\begin{array}{c}\text { Kaneko } \\
(2015)\end{array}$ \\
\hline
\end{tabular}

\section{THE PIEZORESISTIVE SENSOR}

According to [5], sensors are devices whose objective is to convert energy from one domain to another. The principle of operation of the GoP sensor is the piezoresistive effect shown in Equation 1. This effect is characterized by a reversible change in the resistivity, $\Delta \rho_{\mathrm{i}, \mathrm{j}}$, of the material under mechanical stress $[5,6]$.

The piezoresistivity is determined by Equation 1, where, $\pi_{\mathrm{ijkl}}$, is the piezoresistive coefficient tensor, which is a result of the material composition that can be changed by specific doping techniques and the, $\mathrm{T}_{\mathrm{kl}}$, is the mechanical stress undergone by the sensor [5]. Since the electrical resistance depends on the resistivity and the physical dimensions of the conductor as shown by the Ohm's second law (Equation 2), it is crucial to have control over all these parameters when manufacturing a piezoresistive sensor.

$\frac{\Delta \rho_{i j}}{\rho}=\pi_{i j k l} T_{k l}$
$R=\frac{\rho L}{A}$

Usually, strain gauges comprise a cantilever beam made of any flexible material together with a material whose electrical resistance changes when subjected to deformation, so that they can measure the deformation and the force applied to the cantilever. The sensor studied in this paper is pictured in Fig. 1 where the cantilever material is cellulose paper A4 with thickness $88 \mu \mathrm{m}$, the graphite used is a commercial graphite cylinder whose chief properties are presented in Table I, and copper terminals bonded by silver ink contact node.

Fig. 1 illustrates the electromechanical characterization procedures of the manufactured piezoresistors showing details of the graphite film on the polymeric substrate and the region of application of the force [9].

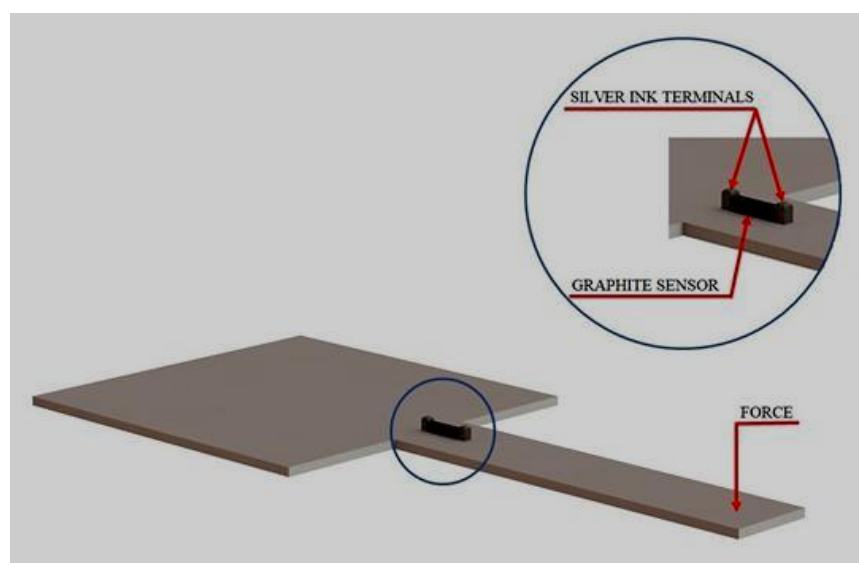

Fig. 1 Schematic of the cellulose paper cantilever with the sensor on it.

The graphite sensor manufacturing process consists of the mechanical exfoliation of a commercial graphite cylinder on the paper substrate, where the graphite layers are deposited, observing that the exfoliation always occurs in the same direction according to the processing steps described in the Fig. 2. The greater the number of graphite layers depositions, the smaller is the sensor 's electrical resistance. Therefore, when the sensor achieves the desired electrical resistance, it is ready for the next step of the production, where the copper terminals are attached to the sensing element by a silver ink as shown in Fig. 2 [9]. 


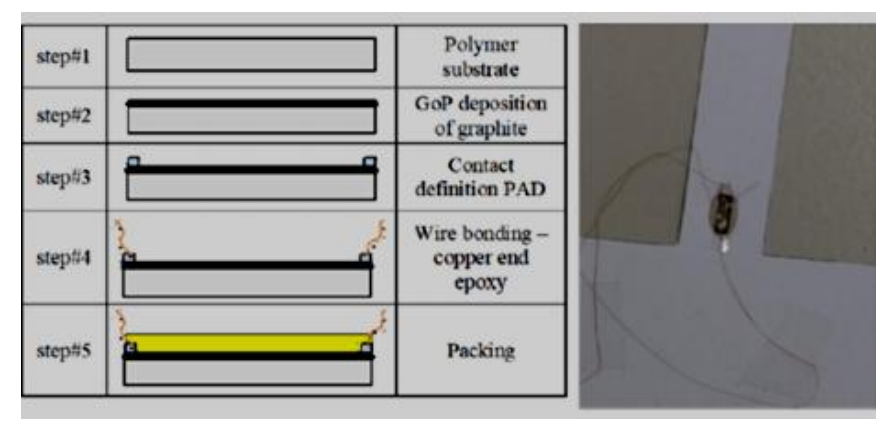

Fig. 2 Processing and photography steps of a manufactured piezoresistor.

Although this kind of sensor is composed of ordinary materials, it shows to have good efficiency, since it has a relatively big change on its electrical resistance over the mechanical strain (Gauge Factor) as shown in the paper [4], therefore showing to be an alternative to semiconductor strain gauges.

\section{MACHINE DESIGN}

The machine development followed the project needs, where it is supposed to deposit the graphite in uniform layers along the "X" and "Y" axis (the plane parallel to the base). The deposition tool uses a hardness HB commercial $0.5 \mathrm{~mm}$ diameter graphite cylinder to make the manufacturing as affordable as possible. The deposition of graphite, along with other factors, is believed to depend on the exfoliation pressure while depositing the graphite on the paper, so that a pressure control system is required. All the hardware was designed using the software CAD Dassault Solid Works.

As deformations can directly influence the machine precision, all its frame was designed in steel, thus offering the necessary robustness to support all the other elements that compose the machine. The frame comprises two main parts, the base, and the $\mathrm{X}$-axis holders.

The work area composes a table made of printed ABS (Acrylonitrile Butadiene Styrene) covered by a flat glass aiming to have a smooth and even surface while having lightweight so that allowing the use of small power stepper motors to move it. The table slides along the $\mathrm{Y}$-axis through a steel linear shaft guidance system, and it uses a threaded rod coupled to a stepper motor to move along the axis.

Stepper motors control the $\mathrm{X}$-axis and $\mathrm{Y}$-axis to obtain precisely the position of the table along the $\mathrm{Y}$-axis and the deposition tool along the $\mathrm{X}$-axis. The deposition tool slides along the Z-axis through linear shafts just like the other two axes, although its movement is provided by a DC motor, since it does not need a precise position control but a pressure control, and this is carried out by a load cell measuring the load applied by the tool.

Fig. 3 shows details of the ABS support of the $\mathrm{Z}$ axis with grooves to facilitate the sliding of the linear axes inside and compartment for the allocation of the load cell.
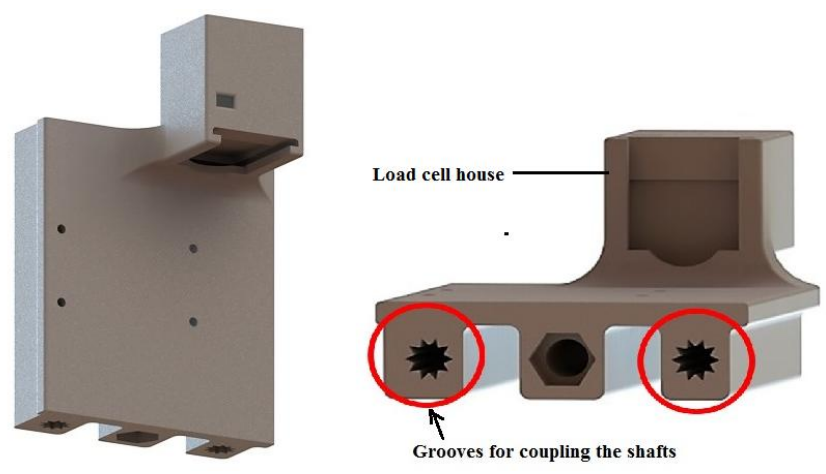

Fig. 3 Details of ABS parts of the axle holder and load cell

In this same part shown in Fig. 3, a housing was also designed for the converter module and amplifier for the electronic signal of the load cell control.

Fig. 4 shows details of the housing for the electronic module.

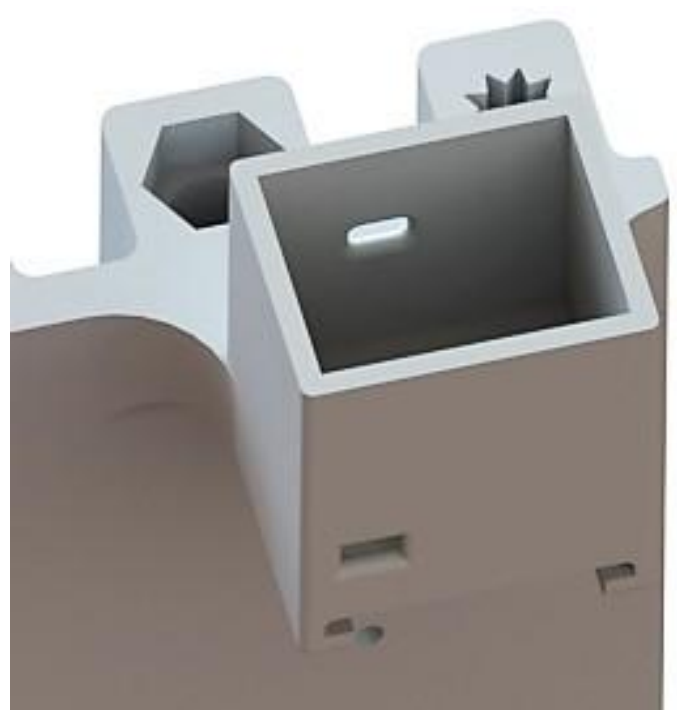

Fig. 4 ABS part details for the electronic signal conversion module

On the $\mathrm{Z}$ axis there is a part as shown in Fig. 5 whose purpose is to support a moving part responsible for transmitting the compression tension of the mechanical pencil to the load cell. This process allows the control of the application pressure of the graphite and, consequently, the control of the thickness of the deposition layer on the paper substrate. 


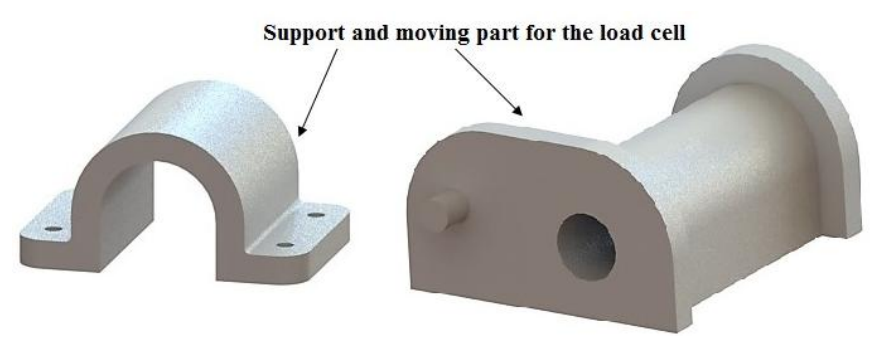

Fig. 5 Moving part responsible for transmitting the mechanical stress to the load cell

The final design, together with its prototype, is illustrated in Fig. 6.
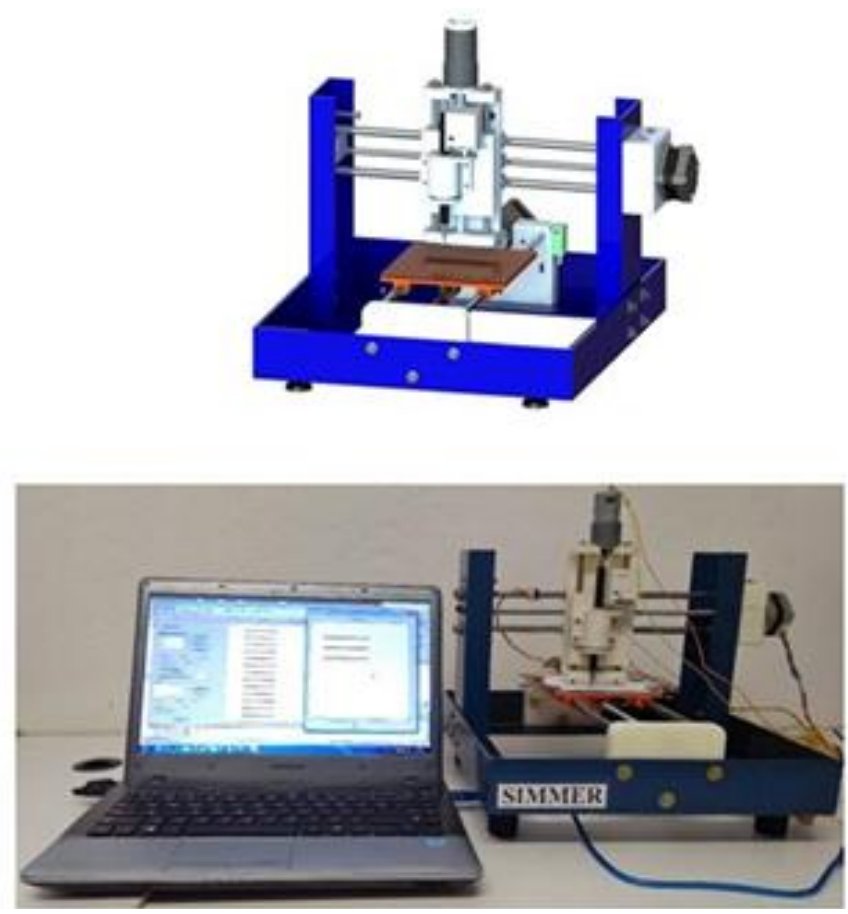

Fig. 6 Machine final design and its prototype.

\section{DESIGN AND MANUFACTURING TOOLS}

In this work, CAD / CAM software to control a machine was also developed. This software was used to assist in the design and manufacture of piezoresistive sensors using the GoP technique. It allows one to design, automate, control, and supervise the manufacturing process of the sensors.

\section{A. Computer Aided Design, Computer Aided} Manufacturing and Firmware

One can determine the material and dimensions for each part of the sensor at the software's design window, which allows one to design the piezoresistive element, its contact PADs, and encapsulation. Once one sets the desired material for the element, it is necessary to define at least three of the fundamental parameters, which are: width, length, thickness, and electrical resistance. If all parameters are set, it will regulate the resistance by modifying the length of the sensor.

During the verification of the sensor parameters, the CAD modifies them until it can be manufactured using the specified material. For example, if the sensor material uses a $0.5 \mathrm{~mm}$ diameter tool, the software will only allow lengths greater than $0.5 \mathrm{~mm}$ and multiple widths of $0.5 \mathrm{~mm}$.

To manufacture the sensors, the machine's CAM generates the commands and enables one to supervise the manufacturing process and ensure that all sensors are according to their specification. This software allows the use of solid materials that are deposited by mechanical exfoliation or liquid materials by injection.

Its manufacturing principle follows the method used by the GoP method described by [8] and [9].

In the graphite mechanical exfoliation process, the software adjusts the pressure of the tool contact with the table and the number of times it does the exfoliation in the same place according to the thickness previously specified. In Fig. 7, one can see the window that shows the behavior of the machine. This window has information concerning the time interval elapsed from the beginning of the manufacturing, and the percentage of the manufacturing process that has been carried out at the time.

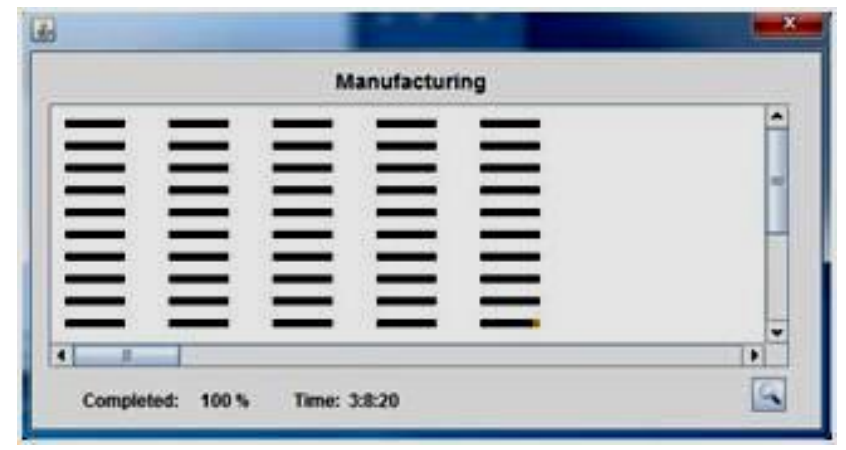

Fig. 7 Software window for production monitoring and control.

The Firmware is responsible for controlling the machine components such as motors and sensors. It contains all the configuration of the machine components. The machine is controlled manually or automatically by the CAM through the communication protocol and sends feedback data on the position of the axes, the value of the sensor pressure and idle capacity.

Its communication with the machine occurs via serial communication on a USB port. The machine communication diagram is shown in Fig. 8. 


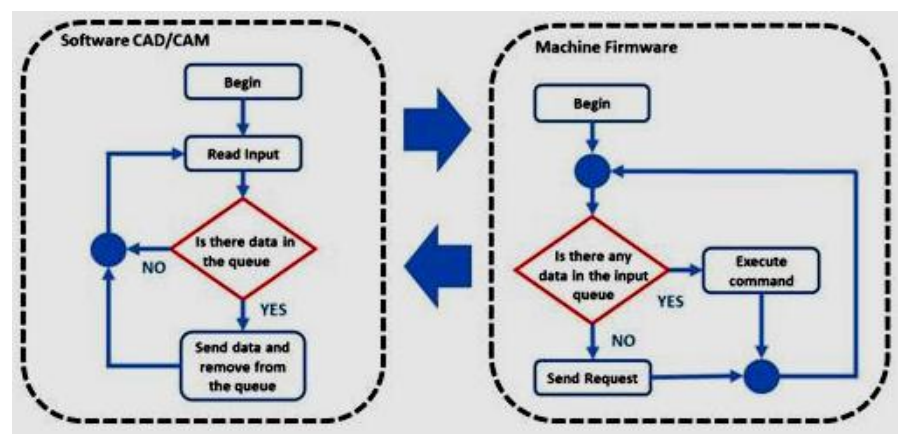

Fig. 8 Machine communication diagram.

\section{TESTS AND SAMPLES}

A set of fifty samples was manufactured to evaluate the machine's behavior where the designed equipment makes the sensor's body by applying a desired force through the graphite on the paper in as many layers as necessary to obtain the desired resistance. These samples use a standard A4 paper whose thickness and dimensions are respectively $88 \mu \mathrm{m}$ and $110 \times 110 \mathrm{~mm}$, the properties of the graphite cylinder used in this experiment are shown in Table I.

Based on [6] the sensor's body size of these samples is $5 \mathrm{~mm}$ in its length and $5 \mathrm{~mm}$ in its width. When compared with the sensors in [6], the sensors manufactured show a decreasing in its width in order to approximate the width of the sensor to the graphite cylinder diameter, so that avoiding potential errors during the deposition. The force applied during the mechanical exfoliation of the graphite was empirically chosen to be $4.905 \pm 0.029 \mathrm{~N}$ in a total of five layers and the space left between each sample was $3 \mathrm{~mm}$ in the $\mathrm{X}$-axis and $2 \mathrm{~mm}$ in the $\mathrm{Y}$-axis.

After the graphite deposition, the next step was to perform a manual adjust aiming to obtain batches of sensors with approximately electrical resistance. This manual adjustment consists of a pressure applied by a metallic tool on the sensor's body, thus decreasing the electrical resistance until achieving the desired value. The samples are shown in Fig. 9, and their results are shown in Fig. 10, and their statistical data are shown in Table II.

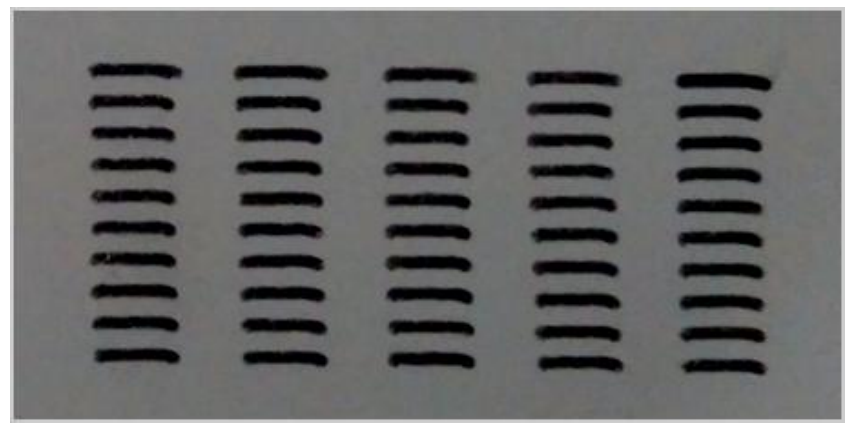

Fig. 9 Graphite piezoresistor samples manufactured with the developed machine.

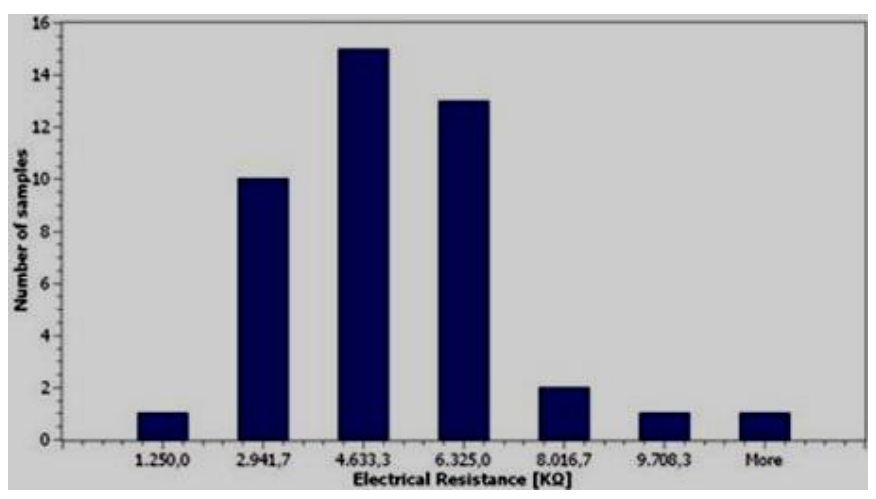

Fig. 10 Histogram of the resistor's electrical resistance machine.

TABLE II

STATISTICAL DATA OF THE SAMPLES

\begin{tabular}{|l|c|c|c|}
\hline \multicolumn{4}{|c|}{ Commercial graphite type HB } \\
\hline Statistic Data & Value & $\begin{array}{c}\text { Unit of } \\
\text { Measurement }\end{array}$ & Source \\
\hline $\begin{array}{l}\text { Maximum } \\
\text { Electrical } \\
\text { Resistance }\end{array}$ & 11400 & $\mathrm{k} \Omega$ & $\begin{array}{c}\text { Multimeter } \\
{[9]}\end{array}$ \\
\hline $\begin{array}{l}\text { Minimum } \\
\text { Electrical } \\
\text { Resistance }\end{array}$ & 1250 & $\mathrm{k} \Omega$ & $\begin{array}{c}\text { Multimeter } \\
{[9]}\end{array}$ \\
\hline $\begin{array}{l}\text { Average } \\
\text { Electrical } \\
\text { Resistance }\end{array}$ & 4370,62 & $\mathrm{k} \Omega$ & - \\
\hline $\begin{array}{l}\text { Standard } \\
\text { Deviation }\end{array}$ & 1956,64 & $\mathrm{k} \Omega$ & - \\
\hline
\end{tabular}

\section{v. FINAL CONSIDERATIONS}

A machine was designed using the software Dassault Solid Works, and its proto-type built following the identified needs. This equipment can deposit graphite layers controlling the applied force with a precision of $\pm 0.029 \mathrm{~N}$ through all the sensor's length. Aiming to automate the manufacturing process a Software was developed in Java programming language to control and monitoring the process.

As the samples have shown, this machine represents an important step toward graphite sensors serial production, although, one can conclude that only force control during the graphite deposition is not enough to obtain sensors with the same characteristics since one cannot ensure paper's and graphite cylinder's homogenous composition.

Graphite is a viable alternative for replacing conventional materials, such as silicon.

Flexible polymeric substrates can be used to manufacture various types of sensor devices and accept different deposition processes. In this work, an automatic machine was designed and built to standardize the deposition of thin graphite films on paper - GoP. 


\section{ACKNOWLEDGMENT}

The authors would like to express their gratitude to the CNPq (National Council for Scientific and Technological Development), FAPERGS (Foundation for Research Support of the State of Rio Grande do Sul) and UNIJUÍ, for the resources to purchase equipment for the construction of prototypes for master's and doctoral research and scholarships for Scientific and Technological Initiation.

\section{REFERENCES}

[1] L. H. Fetike, H.G. Kemper, and T. Feld, M. Hoffmann, "Industry 4.0," Bus Inf Syst Eng, 6, pp. 239 - 242, 2014.

[2] L. A. Rasia, R. D. Mansano, L. R. Damiani, and C. E. Viana, "Piezoresistive Response of ITO Films Deposited at Room Temperature by Magnetron Sputtering," J. Mater Sci.45, pp 4224-4228, 2010.

[3] S. kanaparthi, S. Badhulika, "Low Cost, Flexible and Biodegradable Touch Sensor Fabricated by Solvent-free Processing of Graphite on Cellulose Paper," Sensors and actuators B: Chemical, 242, 857-864, 2017.

[4] R. Gabbi, G. G. MM. Silva, L. Scarton, G. Hammes, L. A. Rasia, A. C. Valdiero," Modelagem Matemática de Elementos Sensores Usando Grafite," Proceeding Series of the Brazilian Society of Computational and Applied Mathematics, 5(1) 1-7, 2017.

[5] P. C. Pedrali, L. A. Rasia, A. C.Valdiero, M. A. Fraga, "Graphite Piezoresistive Sensors In Polymeric Substrates." International Journal of Advanced Engineering Research and Science, 5(10) 105-109, 2018.

[6] R. Berkenbrock, L. A. Rasia, P. C. Pedrali, A. C. Valdiero, "Piezoresistive Graphite Sensors Encapsulated With Epoxy Resin Bisphenol A (Bpa),"American Journal of Engineering Research, 7(4) 148-154, 2018.

[7] S. Kaneko, T. Rachi, M. Yasui, Y. Shimizu, S. Tanaka, C. Kato, T. Endo, "Graphen Growth: 10b Lead Pencil, Print Paper, and Femto Second Laser," In: 2015 International Con-Ference on Microwave and Photonics, ICMAP, Pp. 1-2. IEEE, 2015.

[8] T. L. Ren, H. Tian, D. Xie, Y. Yang, "Flexible Graphite on Paper Piezoresistive Sensors," Sensors, 12(5) 6685-6694, 2012.

[9] L. A. Rasia, P. C. Pedrali, and A. C. Valdiero, "Characterization of Piezoresistive Sensors of Graphite on Paper Substrate," 16th LACCEI International Multi-Conference for Engineering, Education, and Technology: "Innovation in Education and Inclusion", 19-21 July 2018, Lima, Peru. 